\title{
LAND SUBSIDENCE MONITORING WITH MULTI-TRACK SAR DATA
}

\author{
Xi Li ${ }^{1}, \mathrm{Li}$ Yan ${ }^{1, *}$, Guoman Huang ${ }^{2}$ \\ ${ }^{1}$ School of Geodesy and Geomatics, Wuhan University, Wuhan, China - (lixi2019@whu.edu.cn, lyan@sgg.whu.edu.cn) \\ ${ }^{2}$ Key Laboratory of Earth Observation and Geospatial Information Science of NASG, Chinese Academy of Surveying and Mapping, \\ Beijing, China - huang.guoman@163.com
}

Commission III, WG III/3

KEY WORDS: Land Subsidence, Multi-track, NSBAS, Validation, Hebei Plain

\begin{abstract}
:
In this study, we investigated wide-area land subsidence in Hebei Plain using 78 C-band Sentinel-1A SAR images acquired from May 2017 to May 2018 covering two tracks. High-precision time series retrieval was performed by NSBAS technology based on a single track. The offset deformation values of two tracks calculated in this paper were $-0.09 \mathrm{~mm} / \mathrm{year}$, and the multi-track deformation rate was successfully merged. Using the cross-validation of redundant observations in the multi-track overlap area to evaluate the accuracy, and it was found that $90 \%$ pixel difference between the two track overlap areas was within 9 mm. The standard deviation was $5.38 \mathrm{~mm}$, and the subsidence trend of the overlap area was consistent. Twenty-four subsidence bowls were extracted, and the maximum subsidence rate reached $-62 \mathrm{~mm} / \mathrm{year}$.
\end{abstract}

\section{INTRODUCTION}

The Hebei Plain is the northern part of the North China Plain and is one of the areas with the most severe land subsidence in China (Zhang et al., 2014). Groundwater is severely overexploited in Hebei Plain because of water shortage. There are many subsidence bowls in Hebei Plain. Land subsidence is prone to cause geological disasters such as Land subsidence and ground fissures, which has a severe impact on the economic development of Hebei Province. Therefore, it is particularly important to grasp the subsidence development trend in the Hebei Plain.

Early ground subsidence monitoring methods were mainly leveling and Global Positioning System. Synthetic aperture radar interferometry (InSAR) technology is a new space observation technology developed in recent decades (Bamler et al., 1998; Rosen et al., 2000). InSAR time series techniques represented by permanent scatters synthetic aperture radar interferometry (PS-InSAR) method (Ferretti et al., 2001; Ferretti et al., 2000) and small baseline subset (SBAS) method (Berardino et al., 2002) have the advantages of high accuracy and wide monitoring range, etc. InSAR time series techniques have been widely used in urban (Hoffmann et al., 2001), landslide (Fruneau et al., 1996), Earthquake (Massonnet et al., 1993), and other geological disaster monitoring fields. Sentinel$1 \mathrm{~A}$ is a new-generation C-band spaceborne SAR platform. It uses terrain observation by progressive scans mode, which improves the imaging width while ensuring image quality (DAI, 2018). At present, researchers at home and abroad have successfully applied Sentinel-1A data to deformation monitoring in cities and volcanoes, etc.

There are relatively few studies on merging time-series InSAR subsidence monitoring results. A mathematical framework for the datum connection of multiple independent overlapping tracks was proposed, it has been demonstrated that multitrack PS locations can be converted into a common radar datum defined by the master track (Ketelaar et al., 2007). A methodology for developing a Permanent Scatterers (PS) analysis jointly exploiting data acquired from parallel orbits to estimate height and deformation trend of multi-angle urban targets, and it can solve the problem that single-track data could not be reliably retrieved (Perissin et al., 2007). A multi-track PS-InSAR result stitching method was proposed to realize the inversion of large area ground subsidence (Ge et al., 2010). The process of splicing rail-track data using block method and interpolation method was proposed (Xiong et al., 2014). An MT-WabInSAR method was proposed to fuse independent but overlapping track SAR data sets, and applied wavelet-based and Kalman filters to overcome the benchmark and viewing angle differences of overlapping SAR data sets (Shirzaei, 2015). An improved multi-primary image coherent target small baseline interferometric technology (MCTSB-InSAR) was proposed, using three kinds of SAR data to monitor the deformation information of the Beijing-Tianjin-Hebei region from 1992 to 2014 (Zhang et al., 2016). Used interpolation to unify the benchmark and used the offset on the overlapping area to fuse the InSAR results of two adjacent tracks (Sun et al., 2017).

This study took the Hebei Plain as the study area and selected 78 scenes SLC data of the Sentinel-1A satellite of two tracks from May 2017 to May 2018. Precise orbit ephemerides was used to modify the orbit information, and SRTM DEM 1" was used to remove the topographic phase. GAMMA software was used for 2-pass differential interferometry processing, and GIAnT software was used for InSAR time series inversion. High-precision timing inversion was performed based on single track using NSBAS technique. The multi-track deformation rate was successfully merged. It was verified that the subsidence trend of the overlap area was consistent.

\footnotetext{
* Corresponding author: Li Yan,

E-mail address: lyan@sgg.whu.edu.cn
} 


\section{STUDY AREA}

The Hebei Plain is located in the Hebei Province of China and is the northern part of the North China Plain. The study area is outlined by red line in Figure 1, covering most of Hebei Plain. The study area is approximately $45993 \mathrm{~km}^{2}$, covering 114.280 117.610 E and $36.497-38.916 \mathrm{~N}$. The Hebei plain has a flat topography, and the terrain is high in the northwest and low in the southeast. The ground elevation changes from $100 \mathrm{~m}$ in front of the mountain to 2-3m along the Bohai Sea.

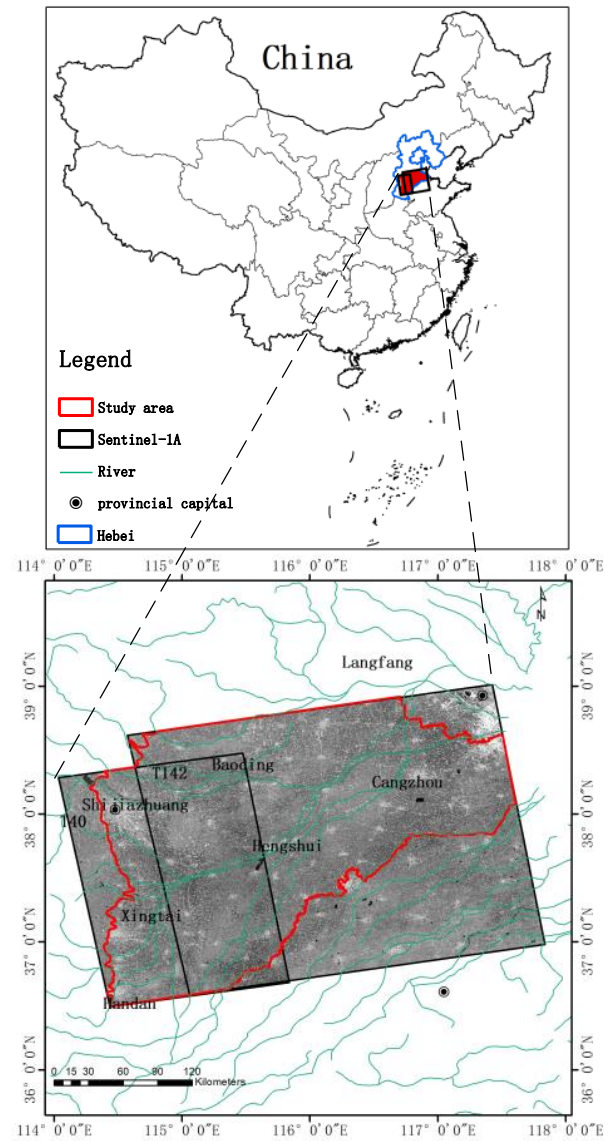

Figure 1. Location of the study area. The black border is the Sentinel-1A data range, the red border is the study area.

The Hebei Plain can be divided into three categories according to the formation type: piedmont alluvial, alluvial slope plain, central alluvial lake plain, and coastal alluvial marine plain. The Hebei Plain belongs to a continental monsoon climate. The annual average temperature is $10-25^{\circ} \mathrm{C}$. The annual precipitation is mainly concentrated in summer, and the spring is less than winter. The annual average precipitation is about $530 \mathrm{~mm}$. The spatial and temporal distribution of average runoff is uneven for many years. There are mainly two river basins, the Haihe River and the Luanhe River.

The ground subsidence of the Hebei Plain started in the middle and late 1950s. From 1965 to 1975, the ground subsidence only appeared in the center of the deep groundwater funnel in Cangzhou City, Hebei Province, and the subsidence rate was generally less than $10 \mathrm{~mm} /$ year. From 1975 to 1985 , the increased exploitation of deep groundwater gradually caused land subsidence.

\section{MATERIALS AND METHODS}

\subsection{SAR Dataset}

3.1.1 Sentinel-1A Data: The Sentinel-1 satellite was launched in 2014, consists of two satellites, Sentinel-1A and Sentinel-1B. This article uses SLC data of Sentinel-1A satellite, and main features are shown in Table 1 . The time span is from May 2017 to May 2018, covering 2 tracks (Track 142, Track 40) with a total of 78 scenes. Among them, Track 142 has 40 and Track 40 have 38 scenes. The list of Sentinel-1A radar data used is shown in table 2 .

\begin{tabular}{c|c|c|c|c}
\hline Band & $\begin{array}{c}\text { Product } \\
\text { type }\end{array}$ & $\begin{array}{c}\text { Acquisition } \\
\text { mode }\end{array}$ & Polarization & $\begin{array}{c}\text { Orbit } \\
\text { directions }\end{array}$ \\
\hline C & SLC & IW & VV & Ascending \\
\hline
\end{tabular}

Table 1. Main features of the SAR data used

\begin{tabular}{cc}
\hline Track 40 & Track 142 \\
\hline $05 / 13 / 2017$ & $05 / 20 / 2017$ \\
$06 / 06 / 2017$ & $06 / 13 / 2017$ \\
$07 / 12 / 2017$ & $07 / 19 / 2017$ \\
$09 / 10 / 2017$ & $09 / 05 / 2017$ \\
$10 / 04 / 2017$ & $10 / 11 / 2017$ \\
$10 / 16 / 2017$ & $10 / 23 / 2017$ \\
$11 / 09 / 2017$ & $11 / 04 / 2017$ \\
$11 / 21 / 2017$ & $11 / 16 / 2017$ \\
$12 / 03 / 2017$ & $11 / 28 / 2017$ \\
$12 / 15 / 2017$ & $12 / 10 / 2017$ \\
$12 / 27 / 2017$ & $12 / 22 / 2017$ \\
$01 / 20 / 2018$ & $01 / 03 / 2018$ \\
$02 / 01 / 2018$ & $01 / 15 / 2018$ \\
$02 / 13 / 2018$ & $01 / 27 / 2018$ \\
$02 / 25 / 2018$ & $02 / 08 / 2018$ \\
$03 / 09 / 2018$ & $02 / 20 / 2018$ \\
$03 / 21 / 2018$ & $03 / 04 / 2018$ \\
$04 / 02 / 2018$ & $03 / 28 / 2018$ \\
$05 / 08 / 2018$ & $04 / 09 / 2018$ \\
& $05 / 03 / 2018$ \\
\hline Table 2. Sentinel-1A data list
\end{tabular}

3.1.2 DEM: The Digital Elevation Model (DEM) from the Shuttle Radar Topography Mission (SRTM), with a $30 \mathrm{~m}$ resolution was used to remove the topographic phase.

\subsection{Methods}

The SBAS method proposed by Berardino et al uses small baseline interferogram pairs composed of multiple master images to inverse deformation. The SAR image is combined into a set of several interferogram pairs. Within the set, the interferogram pairs has a small baseline. Between the sets, the interferogram pairs has a large baseline. The sets are combined to obtain a small baseline interferogram, and the deformation of each set is solved by the least squares method. A singular value decomposition method is used to solve multiple small baseline sets to obtain the deformation rate. 
In the absence of temporal or spatial overlap of independent image groups, the incremental phase delay between successive image groups to zero. It will cause a deviation in the time and thus a deviation in the derformation rate. Lopez-Quiroz et al added constraints to the SBAS time-series inversion instead of using the SVD method, and they proposed a small baseline interferogram network (NSBAS) technology. In order to solve this problem, constraints are added in the time series inversion instead of using the SVD method. If the SBAS network is complete, this method does not affect the inversion and is suitable for data. If the SBAS network is incomplete and has a disconnected subset, then use this method to connect the subset.

\section{RESULTS}

\subsection{Single-track NSBAS Time-series Generation}

Multi-master image baseline estimation was performed on track 40 and track 142 respectively to determine the interferometric pairs combination. Spatial baseline below $200 \mathrm{~m}$ and temporal baseline less than 300 days were designed to generate the interferograms. A total of 170 interferograms from track 40 (Figure 2a) and 190 interferograms from track 142 (Figure 2b) were produced for the time series deformation estimation.
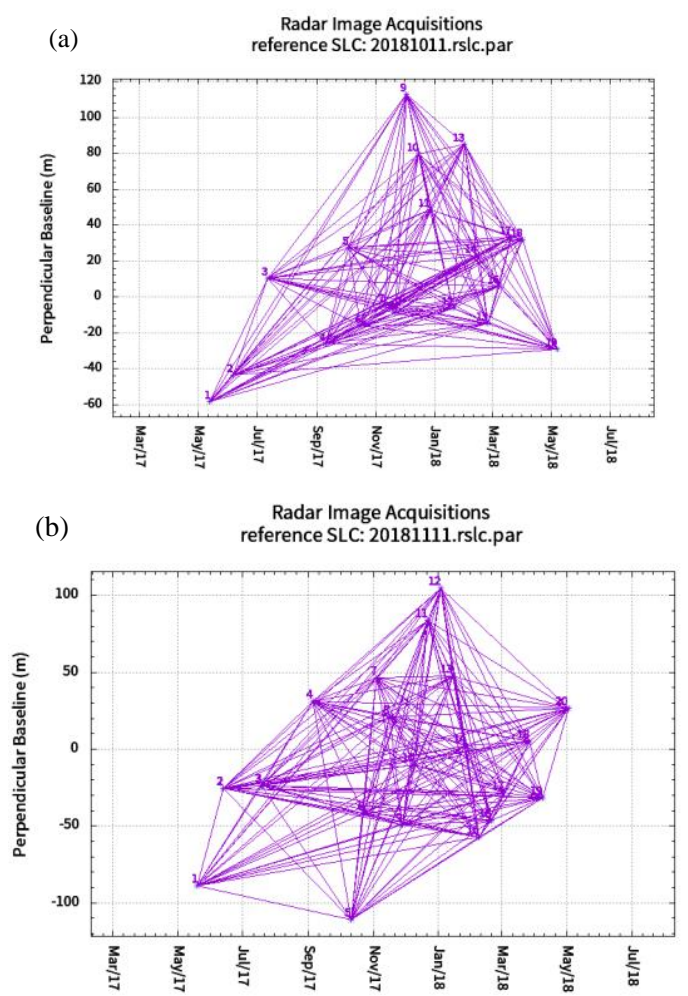

Figure 2. Temporal-spatial baseline distributions of the Sentinel-1A image stacks in this study. (a) Track 40. (b) Track 142 .

Finally, the deformation results in the time series from May 2017 to May 2018 are obtained and cropped, as shown in Figure 3. (a)

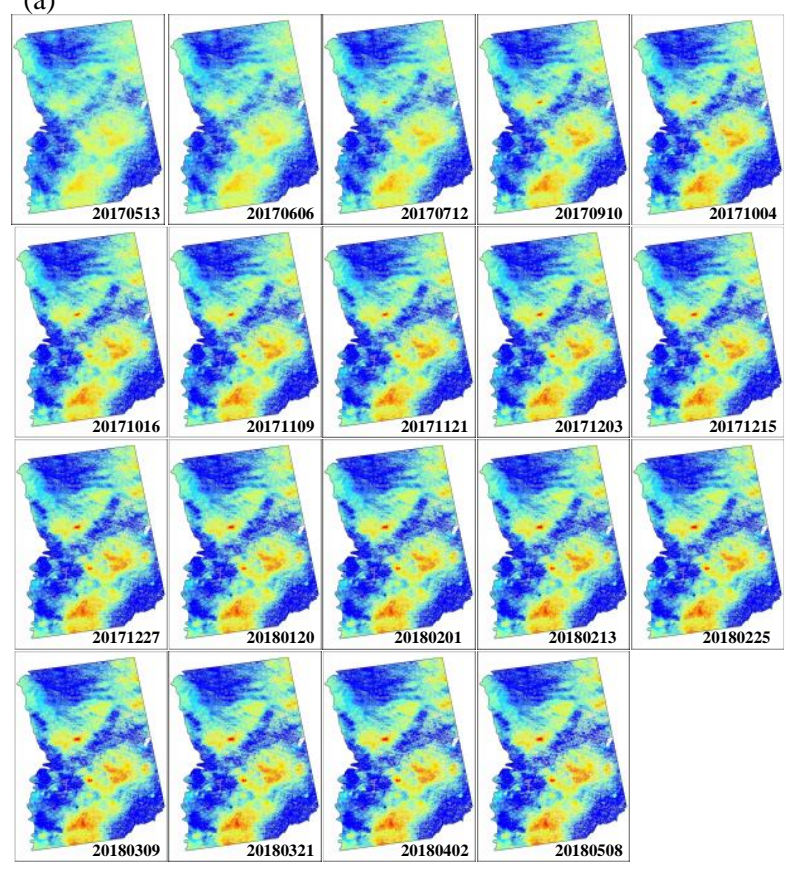

(b)

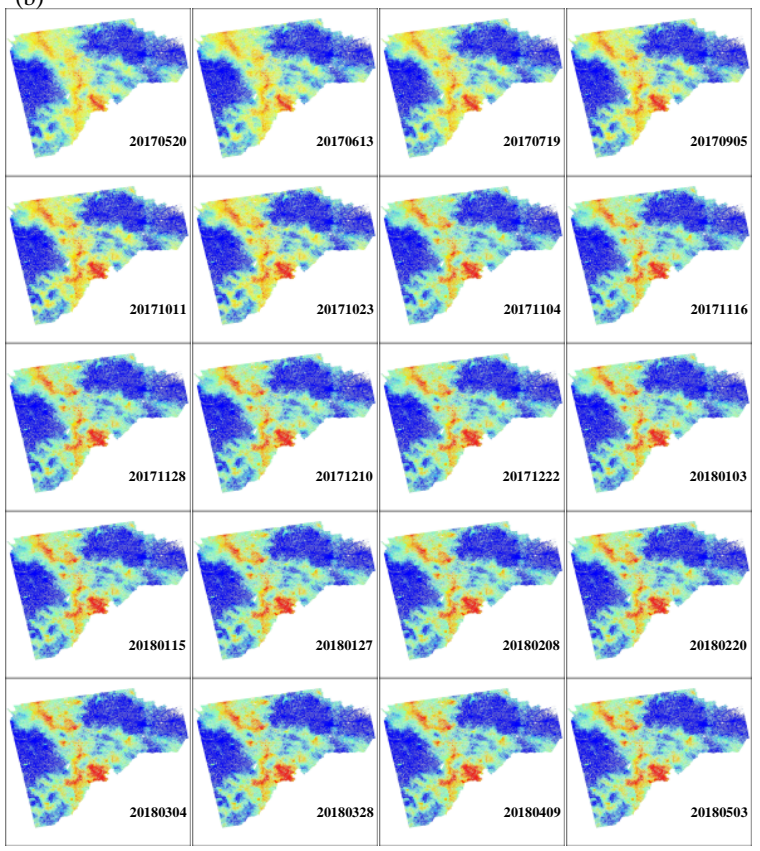

(c)

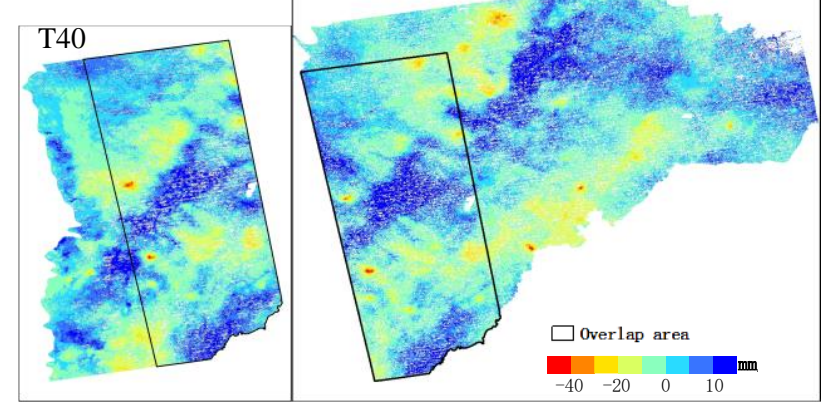

Figure 3. Time series deformation observed using C-band Sentinel-1A images with ascending orbit between May 2017 
and May 2018. (a) Time series deformation on the track 40. (b) Time series deformation on the track 142. (c) Cumulative deformation of two tracks.

\subsection{Merging Multi-Track Deformation Rate}

First program to convert deformation velocity of track 40 and 142 to vector format. Then use the overall coherence file for the evaluation index, extract the PS points with high coherence, and remove the noise points. Secondly, a reference conversion is performed to unify the reference based on the overlapping area. Extract the same coordinate PS points in the overlapping area of two adjacent tracks, make a difference between the deformation values of PS points, calculate the deformation characteristics of the same coordinate points in the two overlapping areas, obtain the reference conversion value, and distribute them according to the weights.

In statistical mathematics, the average is susceptible to extremely small data; the median is only related to the arrangement of the data, and is not affected by the large and small numbers; the mode only relevant to some data in the data. Therefore, this paper uses the median value $-0.09 \mathrm{~mm}$ to convert the reference datum. Since there is no a priori information, it is impossible to determine which track data is more accurate, so the difference of the reference is evenly distributed on the two tracks(Table 3).

\begin{tabular}{c|c|c|c|c|c}
\hline mean & median & mode & $\begin{array}{c}\text { Standard } \\
\text { deviation }\end{array}$ & Min & Max \\
\hline 0.50 & -0.11 & 0 & 5.38 & -33.54 & 31.25 \\
\hline
\end{tabular}

Table 3. PS point difference statistics of overlapping area $(\mathrm{mm})$

The merged cumulative deformation map of Hebei Plain was acquired. A total of 10498468 PS points are shown in Figure 4.

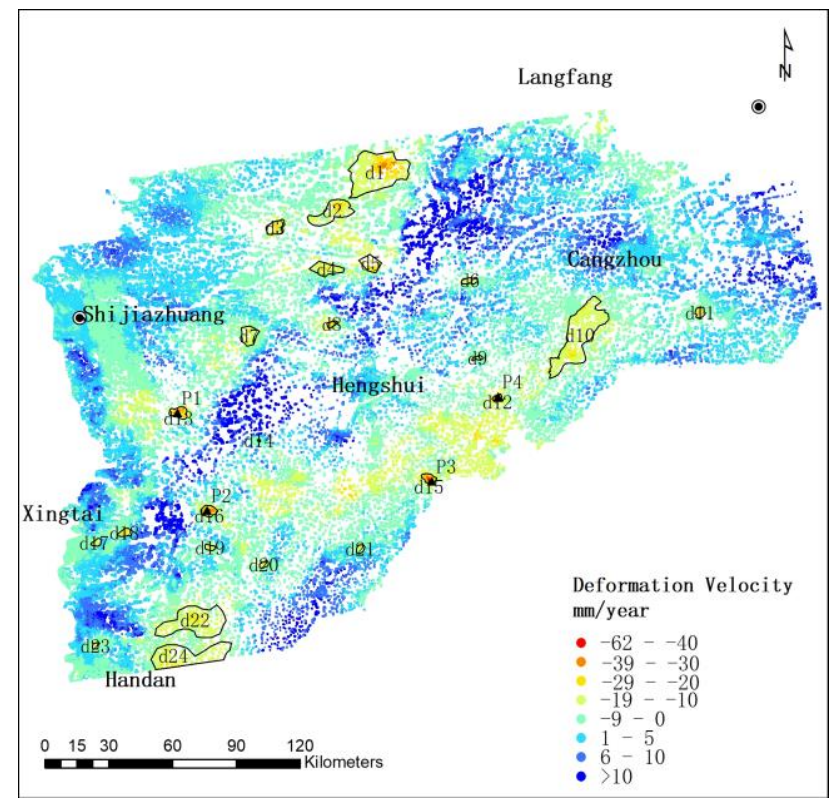

Figure 4. Deformation velocity of Hebei Plain (after merging)

\subsection{Validation of InSAR Results}

Multi-track SAR data processing brings redundant observations to ground subsidence and provides another way of verifying information. In this paper, the histogram method was used to verify the monitoring results of the overlapping areas of track 40 and track 142: the statistical distribution of the difference in the deformation rate in the overlapping areas of the two tracks is counted. The overlapping area of the two tracks covers 13967 $\mathrm{km}^{2}$, and there are 2613343 PS points in total. The histogram of the deformation rate difference of track 40 and track 142 is shown in Figure 5. It can be seen that $90 \%$ of the pixels are located in $[-9,9] \mathrm{mm}$, which is in accordance with the normal distribution, and the standard deviation is $5.38 \mathrm{~mm}$. Therefore, the merging method is reliable, and the result is accurate.

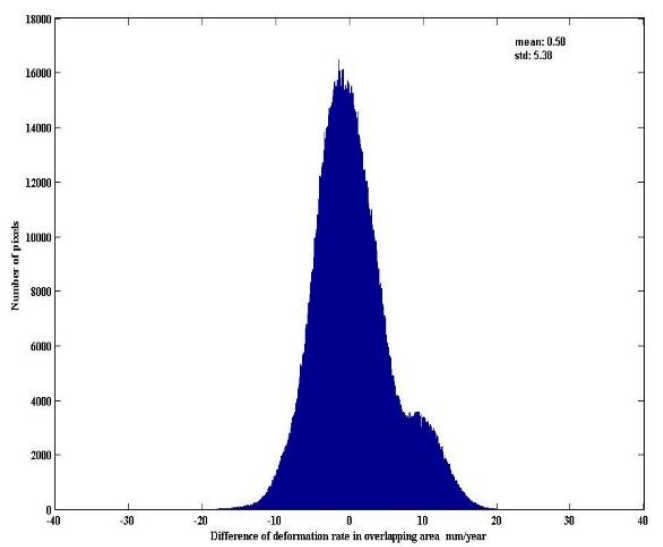

Figure 5. Histogram of overlap zone difference between track 40 and track 142

\subsection{Analysis of Subsidence Monitoring Results}

As can be seen from Figure 4, the distribution of deformation in the Hebei Plain is relatively scattered, there are many subsidence bowls, and there is already a trend of continuous formation in space. The main distribution is shown in Table 4 . The 6 cities monitored all have different degrees of deformation distribution. There are 24 obvious subsidence bowls (Table 5). The maximum deformation rate is located in the deformation area d15- Gucheng County, Xingtai City, which is $-62 \mathrm{~mm} /$ year.

\begin{tabular}{cc}
\hline Cities & Districts \\
\hline Handan & Feixiang,Yongnian, Quzhou \\
Xingtai & Renxian, Pingxiang, Julu, Weixian,Qinghe, Ningjin \\
Hengshui & Gucheng, Jingxian, Shenzhou, Anping, Raoyang \\
Shijiazhuang & Xinji, Zhaoxian, Gaoyi \\
Cangzhou & Dongguang, Botou, Mengcunhuizuzizhixian \\
Baoding & Anguo, Lixian, Gaoyang \\
\hline
\end{tabular}

Table 4. Deformation distribution

\begin{tabular}{ccc}
\hline $\begin{array}{c}\text { Deformation } \\
\text { areas }\end{array}$ & $\begin{array}{c}\text { Maximum } \\
\text { deformation(mm/year) }\end{array}$ & $\begin{array}{c}\text { Minimum deformation } \\
\text { (mm/year) }\end{array}$ \\
\hline d1 & -46 & -3 \\
d2 & -36 & -3 \\
d3 & -31 & -10 \\
d4 & -26 & -4 \\
d5 & -30 & -9 \\
d6 & -22 & -5 \\
d7 & -28 & -5 \\
d8 & -31 & -15 \\
d9 & -17 & -5 \\
d10 & -27 & -5 \\
d11 & -44 & -7 \\
\hline
\end{tabular}




\begin{tabular}{lcc}
\hline $\mathrm{d} 12$ & -48 & -18 \\
$\mathrm{~d} 13$ & -47 & -10 \\
$\mathrm{~d} 14$ & -13 & -5 \\
$\mathrm{~d} 15$ & -62 & -15 \\
$\mathrm{~d} 16$ & -57 & -10 \\
$\mathrm{~d} 17$ & -33 & -3 \\
$\mathrm{~d} 18$ & -32 & -3 \\
$\mathrm{~d} 19$ & -29 & -10 \\
$\mathrm{~d} 20$ & -34 & -9 \\
$\mathrm{~d} 21$ & -25 & -3 \\
$\mathrm{~d} 22$ & -33 & -2 \\
$\mathrm{~d} 23$ & -22 & -5 \\
$\mathrm{~d} 24$ & -30 & -4 \\
\hline \multicolumn{2}{c}{ Table 5. Statistics of 24 major deformation areas }
\end{tabular}

Four points with serious deformation were selected, as shown in Figure 6. It can be seen that the deformation trends of track 40 and track 142 are basically consistent at the subsidence points of $\mathrm{P} 1$ and $\mathrm{P} 2$.
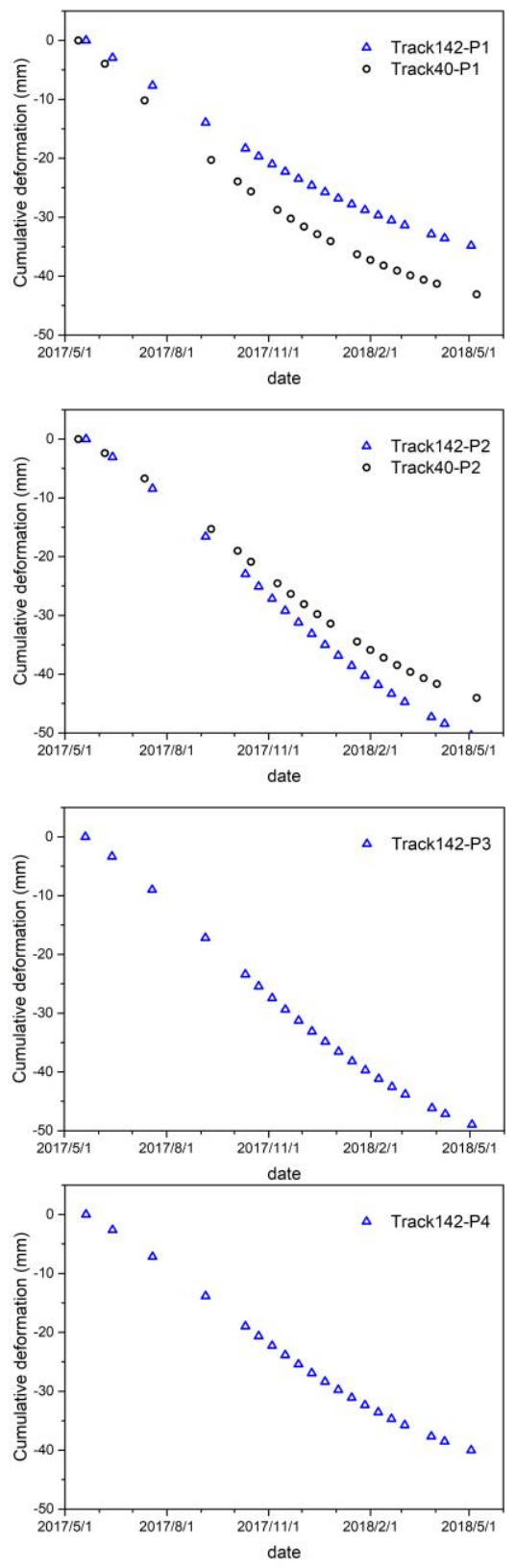

Figure 6. Deformation time series at four typical points (P1-P4), which are located in Figure 4.

\section{CONCLUSIONS}

According to the needs of large-scale ground subsidence monitoring, this paper studied the key technologies of multitrack ground subsidence time series InSAR monitoring. In this paper, the Hebei Plain was used as the research area, and the SLC data of the Sentinel-1A satellite was used. The time span was from May 2017 to May 2018. The 78 scene SAR data of the two adjacent orbits covering the Hebei Plain were respectively analysed. NSBAS technology Time series inversion was carried out, and the multi-track deformation rate was successfully merged. In this study, the following conclusions were obtained: The displacement value of the deformation variables based on the two tracks calculated in this paper was $0.09 \mathrm{~mm}$. Through the unification of the reference datum, the cumulative deformation rate of the Hebei Plain after merging was obtained. Accuracy assessment was performed using crossvalidation of redundant observations in multi-track overlapping areas. It was found that $90 \%$ pixels difference in the overlapping area of the two tracks were within $[-9,9] \mathrm{mm}$. The standard deviation was $5.38 \mathrm{~mm}$, and the deformation trend in the overlapping area was consistent. There were many subsidence bowls and widely distributed. In this paper, 24 main subsidence bowls were extracted and their maximum and minimum deformation information were counted. The maximum deformation rate of Hebei Plain is $-62 \mathrm{~mm} / \mathrm{year}$, which is located in Gucheng County of Hengshui City.

\section{REFERENCES}

Bamler, R., Hartl, P., 1998. Synthetic aperture radar interferometry. Inverse Problems, 14(4). doi.org/ 10.1016/00458732(91)90094-O.

Berardino, P., Fornaro, G., Lanari, R., \& Sansosti, E., 2002. A new algorithm for surface deformation monitoring based on small baseline differential sar interferograms. IEEE Transactions on Geoscience \& Remote Sensing, 40(11), 23752383. doi.org/ 10.1109/TGRS.2002.803792.

DAI, K., 2018. Integration of New Generation SAR Data for Extracting the Earth's Surface Topography and Displacement: Methodology and Modelling. Acta Geodaetica et Cartographica Sinica, 47(3): 422.

Ferretti, A., Prati, C., Rocca, F., 2001. Permanent scatterers in SAR interferometry. IEEE Transactions on Geoscience \& Remote Sensing, 39(1), 0-20. doi.org/ 10.1109/36.898661.

Ferretti, A., Prati, C., 2000. Nonlinear subsidence rate estimation using permanent scatterers in differential sar interferometry. IEEE Transactions on Geoscience \& Remote Sensing, 38(5), P.2202-2212. doi.org/ 10.1109/36.868878.

Fruneau, B., Achache, J., Delacourt, C., 1996. Observation and modelling of the saint-etienne-de-tinée landslide using sar interferometry. Tectonophysics, 265(3-4), 181-190. doi.org/ 10.1016/S0040-1951(96)00047-9.

Ge, D. Q., Wang, Y., Zhang, L., Xia, Y., Guo, X. F., 2010. Large Scale Land Subsidence Monitoring With A Reduced Set 
of Sar Images. Geoscience \& Remote Sensing Symposium, 558561. doi.org/ 10.1109/IGARSS.2009.5417437.

Hoffmann, J., Zebker, H. A., Galloway, D. L., Amelung, F., 2001. Seasonal subsidence and rebound in las vegas valley, nevada, observed by synthetic aperture radar interferometry. Water Resources Research, 37(6), 1551-1566. doi.org/ 10.1029/ 2000wr900404

Ketelaar, G., Leijen, F. V., Marinkovic, P., Hanssen, R., 2007. Multi-track PS-InSAR datum connection. IEEE International Geoscience \& Remote Sensing Symposium, 2481-2484. doi.org/ 10.1109/IGARSS.2007.4423346.

Lopez-Quiroz, P., Doin, M. P., Tupin, F., Briole P., Nicolas, J. M., 2009. Time series analysis of Mexico City subsidence constrained by radar interferometry. Journal of Applied Geophysics, 69(1):1-15.doi.org/ 10.1016/j.jappgeo.2009.02.006.

Massonnet, D., Rossi, M., Carmona, C., Adragna, F., Peltzer, G., Feigl, K., Rabaute, T., 1993. The displacement field of the landers earthquake mapped by radar interferometry. Nature, 364(6433), 138-142. doi.org/ 10.1038/364138a0.

Perissin, D., Prati, C., Engdahl, M. E., Desnos, Y. L., 2006. Validating the sar wavenumber shift principle with the ersenvisat ps coherent combination. IEEE Transactions on Geoscience and Remote Sensing, 44(9), 2343-2351. doi.org/ 10.1109/TGRS.2006.875455.

Rosen, P. A., Hensley, S., Joughin, I. R., Li, F. K., Madsen, S. N., Rodriguez, E., Goldstein, R. M., 2000. Synthetic aperture radar interferometry. Proceedings of the IEEE, 88(3), 333-382. doi.org/ 10.1109/5.838084.

Shirzaei, M., 2015. A Seamless Multitrack Multitemporal InSAR Algorithm. Geochemistry Geophysics Geosystems, 16(5): 1656-1669. doi.org/ 10.1002/2015GC005759.

Sun, H., Zhang, Q., Zhao, C., Yang, C., Sun, Q., Chen, W., 2017. Monitoring land subsidence in the southern part of the lower liaohe plain, china with a multi-track ps-insar technique. Remote Sensing of Environment, 188, 73-84.

Xiong S. T., Zeng Q. M, Jiao J., Zhang X. J., 2014. Research on Connecting PS-InSAR Results from Adjacent Tracks for Land Subsidence Monitoring, 16(05):797-805. doi.org/ 10.3724/SP.J. 1047.2014.00797.

Zhang, J. C., Chu, L. F., Xiao, Z., Lu Z. C., Shen, R. H., Chen, Y. J., 2014. Main progress and achievements of land subsidence Survey and monitoring in Hebei Plain. Geological Survey of China, 1 (02): 45-50.

Zhang, Y., Wu, H., Kang, Y., Zhu, C., 2016. Ground Subsidence in the Beijing-Tianjin-Hebei Region from 1992 to 2014 Revealed by Multiple SAR Stacks. Remote Sens, 8, 675. doi.org/ 10.3390/rs8080675. 